OPEN ACCESS

Edited by:

Anabela Carvalho,

University of Minho, Portugal

Reviewed by:

Weimin Toh,

Nanyang Technological University,

Singapore

Ana Patrícia Oliveira

University of Aveiro, Portugal

*Correspondence:

R. Lyle Skains

Iskains@bournemouth.ac.uk

Specialty section:

This article was submitted to

Science and Environmental

Communication,

a section of the journal

Frontiers in Communication

Received: 05 October 2021 Accepted: 21 December 2021

Published: 27 January 2022

Citation:

Skains RL, Rudd JA, Horry $R$ and Ross H (2022) Playing for Change: Teens' Attitudes Towards Climate Change Action as Expressed Through

Interactive Digital Narrative Play.

Front. Commun. 6:789824.

doi: $10.3389 /$ fcomm.2021.789824

\section{Playing for Change: Teens' Attitudes Towards Climate Change Action as Expressed Through Interactive Digital Narrative Play}

\author{
R. Lyle Skains ${ }^{1 *}$, Jennifer A. Rudd ${ }^{2}$, Ruth Horry ${ }^{3}$ and Helen Ross ${ }^{4}$ \\ ${ }^{1}$ Department of Communications and Journalism, Bournemouth University, Poole, United Kingdom, ${ }^{2}$ School of Management, \\ Swansea University, Swansea, United Kingdom, ${ }^{3}$ Department of Psychology, College of Human and Health Science, Swansea \\ University, Swansea, United Kingdom, ${ }^{4}$ Helen's Place Education Consultancy, Wiltshire, United Kingdom
}

We designed and pilot tested "You and $\mathrm{CO}_{2}$ ", a program designed to encourage students to reflect on their personal impact on the environment, while also appreciating their place within society to bring about positive societal change. Over three interlinked workshops, students analysed the carbon footprints of some everyday activities, which they then explored in more detail through interacting with a bespoke piece of interactive digital narrative (IDN), No World 4 Tomorrow. Previous papers have discussed the feasibility of the program and student engagement with the concepts. This paper presents analysis of the playthrough data as each participant in the program played the IDN to completion, examining trends in story selection choices for how they reflect students' understandings and attitudes towards climate change and their own ability to make a difference in matters large and small pertaining to climate change.

Keywords: climate change education, interactive digital narrative, serious games, science education, entertainment as education

\section{INTRODUCTION}

The United Nations identifies catastrophic climate change as the defining issue of our time, requiring urgent and drastic change (United Nations 2016). Because of its universality, however, many people feel powerless: that one individual cannot affect such an enormous problem. The effect of "diffusion of responsibility" (Wegner and Schaefer 1978) is significant: we feel we share responsibility with all seven-plus billion people on Earth, and thus our individual responsibility is minimized. Likewise, because the worst contributors of greenhouse gases are corporations operating legally (Griffin 2017), and disastrous effects are relatively long-term and incremental, individuals feel less driven towards action (Gifford 2011). Education efforts, therefore, must urge individuals not only to alter their own behaviour patterns contributing towards carbon footprints, but also to take action to effect change on a much larger scale: governmental and corporate structures.

We have piloted one such educational effort, "You and $\mathrm{CO}_{2}$ " (YCO2) (a full profile of the program is included in Rudd et al., 2019). YCO2 is an interdisciplinary project, using combined arts and science workshops in British secondary schools (students aged 12-15) to encourage students to reflect on both their own personal contributions to climate change, and to consider how they can engage with the wider societal systems that drive climate change. This age group was selected for several reasons: 1) our existing network of teachers and schools that could participate in the project were secondary schools; 2) this is a key age in which children are 
learning to make their own decisions and influence family culture, and they are shaping their ideas of the world and their place within it, 3 ) adolescents are more likely to be affected by climate change than most adults (Lutz 2001; Cornelius et al., 2014; van Borries et al., 2020). The workshops encompass an innovative combination of interactive chemistry lessons, reading, and discussion of interactive digital narratives (IDNs) for themes of climate change and personal choice, and student construction of their own IDNs on themes of climate change and personal responsibility. This learning intervention is a multiliteracies approach (Cope and Kalantzis 2009; Skains 2019b) to teach the science of climate change through digital literacy, interactivity, creative writing, game design, discussion, and group and individual work. Multiliteracies is a design-based pedagogical approach that develops multiple professional, developmental, and cognitive skills through the holistic layering of multiple practical activities within any given course or lesson. Our working hypothesis is that reading and writing IDNs increases young people's attention to the content, and thus will embed these lessons on multiple levels; this increases the likelihood that the students will take active steps to decrease their personal carbon footprints and combat climate change through personal and political activism. Previous and concurrent studies in this area indicate that serious games and interactive narratives increase students' understanding of STEM topics (Ferrara 2013; Lester et al., 2014; Mayer 2014; Cheng et al., 2015; Moezzi et al., 2017) including concepts central to climate change (Harker-Schuch et al., 2020). Few studies, however, have specifically examined the more narratively-oriented IDN as a climate change education tool, though it has been studied as effective psychological interventions for young people with body image issues (Ensslin et al., 2016).

These workshops generate data in several ways, as discussed more thoroughly in the Method section: we survey the students regarding their knowledge of and attitudes about climate change before and after the program intervention; we collect the work the students create on the project for qualitative analysis yielding insights into their engagement with the program; and we collect playthrough data every time a student plays the project IDN, recording the links they click throughout the interactive story. This paper focuses on this last element of data, examining the choices the students make in navigating the story, and how these choices reflect their attitudes about climate change, as well as their engagement with the IDN itself. Engagement in the intervention is a key element contributing to attitude and potential behaviour change regarding the climate crisis (Höppner and Whitmarsh 2011; Rabinovich et al., 2011; Bostrom et al., 2019), thus it is important to attempt to measure this cognitive engagement, as complex as that may be. We have previously conducted qualitative analysis of the studentcreated IDNs for indications of their engagement in the overall YCO2 program, creating a model as an aid to identifying barriers to engagement (Ross et al., 2021). The analysis included in this paper narrows the focus from the entire YCO2 program to the specific IDN used as bibliotherapy (Pardeck 2014), or reading/playing for attitude and behaviour change.

\section{METHODS}

\section{Overview of Program}

The YCO2 program consists of three workshops of one to 2 hours each, depending on the school, class, and instructor needs. Likewise, according to needs and schedules, instructors may conduct the workshops on subsequent days, or spread them out over the course of several weeks or months. All teaching materials are available on the program website (http://youandco2. org/), including lesson plans, activity worksheets, discussion questions and prompts, and rubrics, as well as the program IDN No World 4 Tomorrow and tutorials for the students to create their own IDNs. The full description of the program can be found in Rudd et al., 2019.

The workshops were conducted by the researchers (Rudd and Skains) in Spring 2019 in person in Valley and Heighton schools (school details below), using school-provided equipment and IT support: Valley provided desktop or Chromebook computers, while Heighton students had individual tablets of varying brands. At the latter two schools, Clearend and Summervale, the class teachers delivered the workshops in in-person classes in Spring 2021 using school-provided equipment and IT support, subsequent to training sessions from the researchers.

Prior to Workshop 1, students complete a survey measuring their knowledge of and attitudes regarding climate change (see Horry et al. in review for survey development). Workshop 1 is focused on the chemistry and mathematics of climate change: after a demonstration of the molecular chemistry of carbon production, the students calculate their own carbon footprints for their typical morning activities. They then form groups with the task of reducing the group's combined footprint by one-third through negotiating their activities for those with lower impact, and discuss their strategies through presentations and class discussion. This workshop's multiliteracies activities combine mathematics, chemistry, group communication, negotiation, and presentation.

Workshop 2 is a reading of the custom-built IDN for the project, No World 4 Tomorrow (Skains 2019a); the instructor chooses whether to lead a group reading of the IDN using a projector, to have the students play through the IDN individually on separate digital devices, or some hybrid of the two, depending on class make-up and abilities. This workshop's multiliteracies activities combines reading, digital skills, discussion, and considering options and choices in fictional versus real-world scenarios.

Workshop 3 incorporates research, writing, and digital literacy skills, in that the students are then tasked with designing and creating their own IDNs on the topic of climate change, either in small groups or as individuals. The $\mathrm{YCO} 2$ program provides an online tutorial for this workshop, as well as a story prompt exercise for any students who struggle to find what to write about. Students submit their IDNs on a voluntary basis to the 
researchers, and complete the final project survey on climate change knowledge and attitudes. This workshop's multiliteracies activities incorporate research, creative storytelling, writing, intermediate digital skills, and critical thinking.

\section{Constructing the IDN}

The project's IDN, No World 4 Tomorrow (NW4T), was purposebuilt for this project by the first author; a full discussion of the practice-based approach, challenges, choices, rationales, and activities appears in Skains et al., 2019. Its communicative purpose was to effect positive behaviour change regarding climate change action, inspiring its target audience through creation of an emotional connection, in line with existing literature on educating through entertainment media (Huffaker and Calvert 2003; Singhal et al., 2003; Sood et al., 2003; Resnick 2004; Rapeepisarn et al., 2006; Dahlstrom 2014). Arvind Singhal et al. (2003) recommend specific strategies for entertainment-media-as-education: focusing on relatable characters, achieving message saturation through repetition and word of mouth, encouraging small iterative changes in the audience, encouraging self-efficacy, and complying with the audience's cultural values and norms so that they do not reject the message. Further, it is important that any climate change education program engender a feeling of hope, offering positive motivation to enact change (Pruneau et al., 2001). Creating these emotional connections entails designing a story with strong characterisation and a good narrative arc-making the quality of the story the primary aim for the work, so that its audience will not only connect with it individually to take its message on board, but also to enjoy it sufficiently to share with peers, teachers, and parents for greater message saturation and long-tail (Anderson 2006; Brown and Adler 2008) longevity for the work.

Background research for constructing the IDN included reviewing narratives, themes, and genres popular with the target age group: the Maze Runner series (Dashner 2013), Simon vs. the Homo Sapiens Agenda (Albertalli 2015), the Ship Breaker series (Bacigalupi 2010), and Deadpool (Nicieza and Liefeld 1991). We determined that audiences in our target demographics enjoyed narratives with humour, a slightly older main character (age 16-18), personalisation, social media, love interests (including open approaches to sexuality), selfrealisation, feelings of control, and mystery/adventure. Based on our goals for the IDN and this audience research, we identified the following constraints for the work:

1) The IDN must be relatable for the audience (localised to their experience and culture, with options for custom personalisation)

2) It must allow the reader/player to make choices to direct the narrative that reflect everyday actions related to climate change

3) It must encourage feelings of hope, engendering the reader/ player to feel in control and that their actions have meaning (self-efficacy)

We sought to counter diffusion of responsibility (Wegner and Schaefer 1978) in NW4T by creating a microcosm of a planet- wide problem, embedding the narrative in a much smaller community where individual actions would be more apparent, and have more immediate effect. This resulted in NW4T's setting as a lunar colony, a small population of adventuring residents with very limited resources and a strong need to function cooperatively as a community. The reader/player enters their name and the names of friends or family members, all of whom become characters in the story, engendering greater emotional connection to the narrative. We added a "faction" of the community working counter to this goal, whose inappropriate use of resources enables the reader/player to make choices about not only individual actions, but also society's actions; this narrative parallels real-world options about individual carbon footprints, as well as the path of activism that aims to affect wider society's actions regarding climate change.

The IDN was built using Twine (Klimas 2009), a free, opensource, browser-based authoring tool specifically for creating IDNs; the resulting IDN is an HTML file deployable as a website that can be read on any digital device (including both mouse-driven and touch-tap). In response to technical limitations in many United Kingdom schools, as well as the understanding that participants would likely want to imitate mechanical elements in their own IDNs in Workshop 3, NW4T used relatively few multimedia or advanced gameplay techniques. Participants began the IDN by inputting a codename (a combination of letters drawn from their birthdate, address, family members, etc.) that was both unique to each student and reconstructable should they forget it; the codename was used not only for access to the IDN, but also on both surveys and the student-created IDNs, enabling anonymous linkage of all collected data. The narrative begins with a prompt to enter their name and pronouns, and the names and pronouns of their three most frequent contacts, which are then populated throughout the narrative for personalisation.

Text was displayed over a consistent background image (a public-domain NASA photo of Earthrise from the lunar surface), with only one additional photo appearing in the narrative. The text was in a sans-serif font in a contrasting shade (light grey on the black starscape background) to aid special educational needs in terms of general understandability. Links leading to new passages, including several "pop-up" passages that offer exposition on specific story topics, were coloured orange and underlined; "cycling links", which do not lead to new passages but act as multiple choice options, changing their text each time they are clicked/tapped (e.g., for lunch options), were teal, underlined. For greater accessibility, words and phrases requiring a higher reading level were mouse-over/tappable (green, underlined); mousing over/tapping resulted in audio playing United Kingdom pronunciation of the word, and the word to cycle to a simpler synonym or phrase. The audio could be muted if desired. Several sections included an overlay image of the reader/player's "comm" (essentially, a mobile phone) that included animated messages between them and their community; these advanced with clicks/taps, enabling reading at varying speeds for accessibility.

Six different endings were incorporated into NW4T to allow the participants to see the effects of their choices: the reader/ 
player becomes a climate change activist urging wider societal change, an eco-warrior with strong personal commitment to the environment, a neutral citizen who neither harms nor aids in the crisis, a slightly irresponsible citizen whose actions contribute in a small way to the crisis, a neglectful citizen whose actions contribute significantly to the crisis, or an outright villain whose selfish actions will directly lead to destruction of the community. The choices the reader/player makes in traversing the IDN are both macro-choices leading to differing narrative pathways for each of the possible endings, or micro-choices that reflect on the reader/player's individual actions; regardless of which ending is achieved, the reader/player receives a comment on how their smaller actions, like choosing transport methods or what to eat for lunch, affect their environment.

Finally, NW4T included functionality to record participant choices, which is not a standard feature of Twine. Significant choices in the story, both micro- and macro-, were labelled with variables, as were the end states of each playthrough; at the conclusion of the playthrough, these compiled into a JSON list sent to a designated Google Sheet. This playthrough data is arranged by anonymous codename, and records how many different playthroughs each codename completes. Once captured, the data is stored on password-encoded drives in compliance with the approved ethics for this project.

\section{Participant Demographics}

The data in this paper was collected from four different schools in Wales and England; names of schools and participants have been anonymised in this discussion to maintain anonymity of the data. Participants were selected based on teachers who volunteered to incorporate the program into their existing curricula; variations in implementation and participant groups exist because of teacher preferences in the classrooms running the programs, as well as scheduling and logistical concerns depending on school timetables, planned curricula, special events, and researcher availability. Participants could withdraw or withhold their data. Drop-outs occurred when students were not present at any of the workshop sessions, or if they did not submit or withdrew their data.

Valley School is a large (1800 students) school in South Wales, rated Excellent in the most recent Estyn, 2018 inspection prior to running the YCO2 program. The school ethos incorporates a "School Advisory Board" where students can contribute to school-related discussions and decisions; the Estyn report notes that the Key Stage 3 students' literacy skills are strong, and the students approach real-life problems with confidence. YCO2 was taught to 85 students from three high-ability Year 9 (age 13-14) classes in 1-h sessions with approximately 1 month between each. The students shared computers to read/play NW4T in Workshop 2.

Heighton School is a smaller independent school (200 students) in North Wales, with 32\% international students. The Estyn report ranked Heighton between "Good" and "Adequate and Needs Improvement": students were keen learners, but instruction was often not differentiated sufficiently to suit varying students' needs. YCO2 was taught to three classes of approximately 30 students each, one each from
Years 8 , 9, and 10 (age 12-15). Workshop 1 was 1 hour, while Workshops 2 and 3 were both 2 hours; all three workshops were taught on successive days as part of a special STEM week. Workshop 2 was conducted in the hybrid model: the first read-through was done as a whole class, with the work displayed on a projector and the students suggesting which options to click (approx. $45 \mathrm{~min}$ ). Students were able to use individual devices (primarily tablets) for the remaining time in the session to read/play NW4T as many times as they liked, with a prompt to see how many endings they could find.

Clearend Middle School is a small middle school in Northern England with 300 pupils across Years 6, 7, and 8. The school was rated "Good" by Oftsted and it was noted that "pupils have also participated in research" (UK Government 2019). YCO2 was taught to one Year 8 (age 12-13) class of approximately 30 students. Workshops 1 and 2 were both conducted in December 2020; unfortunately, a regional increase in COVID19 infection rates prompted the school to close early for the winter holidays, and thus Workshop 3 could not run. Workshop 2 was conducted in the hybrid model: the first read-through was done as a whole class, with the work displayed on a projector and the students suggesting which options to click (approx. $45 \mathrm{~min}$ ). Students were able to use individual devices (primarily tablets) for the remaining time in the session to read/play NW4T as many times as they liked, with a prompt to see how many endings they could find.

Summervale School is a secondary school in South Wales, rated "Good" in the most recent Estyn inspection prior to running the YCO2 program. The school has 1,400 students enrolled across Years 7-13. The school has a high proportion (40\%) of students from economically deprived areas. Approximately 50 students from the school's Year 8 (age 12-13) came to Swansea University as part of an "eco-day". Students were shown around the Bay Campus and were involved in a beach litter pick and a tour of the energy-saving measures on campus. Workshop 2 from YCO2 was then run as an activity as part of the eco-day. Students were given access to NW4T on individual desktop computers. As the group was mixed ability some students struggled to read NW4T without significant assistance and some students had found all six endings within $30 \mathrm{~min}$. Therefore, a group reading completed the activity.

\section{Analysing the Playthrough Data}

The collected data was collated by codename and number of replays. Proportional analysis was manually conducted of the data from a grounded theory perspective, qualitatively reviewing the data to reveal patterns for further analysis, based on the following objectives:

- How many playthroughs each reader/player completed

- Ending achieved compared to replay number

- Micro-choices for:

1) "transport", the first cycling link in the IDN, occurring on the fifth passage, allowing reader/player to choose how they are going to travel to meet up with their friends

2) "lunch", the second cycling link in the IDN, occurring on the sixth passage, allowing the reader/player to choose what they are going to eat for lunch 
TABLE 1 | IDN playthrough proportions.

\section{Unique reader/players}

55 (38.73\%) Played only once 37 (26.06\%) Played exactly twice

21 (14.79\%) Played exactly 3 times 15 (10.56\%) Played exactly 4 times

7 (4.93\%) Played exactly 5 times

$4(2.82 \%)$ Played exactly 6 times

$1(0.70 \%)$ Played exactly 7 times

$1(0.70 \%)$ Played exactly 8 times

$0(0.00 \%)$ Played exactly 9 times

$1(0.70 \%)$ Played exactly 10 times

\section{Cumulative proportions}

142 (100.00\%) Played at least once $87(61.27 \%)$ Played at least twice $50(35.21 \%)$ Played at least 3 times $29(20.42 \%)$ Played at least 4 times $14(9.86 \%)$ Played at least 5 times

7 (4.93\%) Played at least 6 times $3(2.11 \%)$ Played at least 7 times $2(1.41 \%)$ Played at least 8 times $1(0.70 \%)$ Played at least 9 times

$1(0.70 \%)$ Played at least 10 times
3) "activity", the third cycling link in the IDN, occurring on the sixth passage, allowing the reader/player to choose what they are going to do after lunch

4) "protests", the fourth cycling link in the IDN, occurring on the tenth passage, allowing the reader/player to choose an action responding to community uproar over a resource crisis

- Pop-up passage clicks for:

1) "Earth 2", the first pop-up link in the IDN, occurring on the sixth passage, offering information on the topic of conversation at lunch (a virtual reality show called Earth 2.0)

2) "Deeps", the second pop-up link in the IDN, occurring on the seventh passage, offering information on a location termed "the Deeps" (a now-abandoned underground structure that first housed the lunar colonisers)

3) "Gens", the third and fourth pop-up links in the IDN, occurring on the seventh and ninth passages, offering information about the names of the different generations of colonisers present in the community

While more data was collected, these are the only areas that, based on the noted qualitative analysis of proportional trends, yielded any particular patterns.

\section{RESULTS}

Data were collected from 142 unique codenames. 55 of these reader/players $(38.7 \%)$ played the IDN only once; the remaining $87(61.3 \%)$ made at least one repeat playthrough, with one $(0.7 \%)$ completing ten total playthroughs (see Table 1).

Figure 1 shows the trends in endings achieved related to replay number. In their first playthroughs, reader/players most frequently achieved the "good" or "responsible" endings: $69.7 \%$ of reader/players split evenly between activist and eco-warrior. As replays increased, the more negative endings rose, with irresponsible leading at $60.9 \%$ in the second playthrough, neglectful rising to $28.0 \%$ in the third, and $48.3,42.9$, and $57.1 \%$ in the fourth, fifth, and sixth replays, respectively.

Playthrough endings were also reviewed to collate changes between endings on each playthrough for individual reader/ players (see Table 2). Reader/players who achieved a positive (activist, eco-warrior, neutral) ending in their first and second playthroughs were coded "pp"; positive first and negative (irresponsible, neglectful, villain) second were "pn"; negativenegative were "nn"; and negative-positive were "np". $46.1 \%$ of reader/players who replayed the IDN at least once were coded "pn", while "pp" made up $28.2 \%$ of this group.

Micro-choice cycling links begin with little use: the default values for both transport and lunch dominated the first playthrough at 53.5 and $33.1 \%$, respectively. As playthroughs progress, transport shifts from walking to single-occupant transportation in playthrough four ( $44.8 \%$ choosing this option), while salad continues to dominate the lunch options for all playthroughs, though the minority options vary a bit more (see Tables 3, 4).

$43.0 \%$ of reader/players choose to "skive off" (skip school/ work) as their after-lunch activity in the first playthrough (see Table 5). On repeat playthroughs, however, reader/players were more likely to choose going to school; in all playthroughs players were least likely to select going to work.

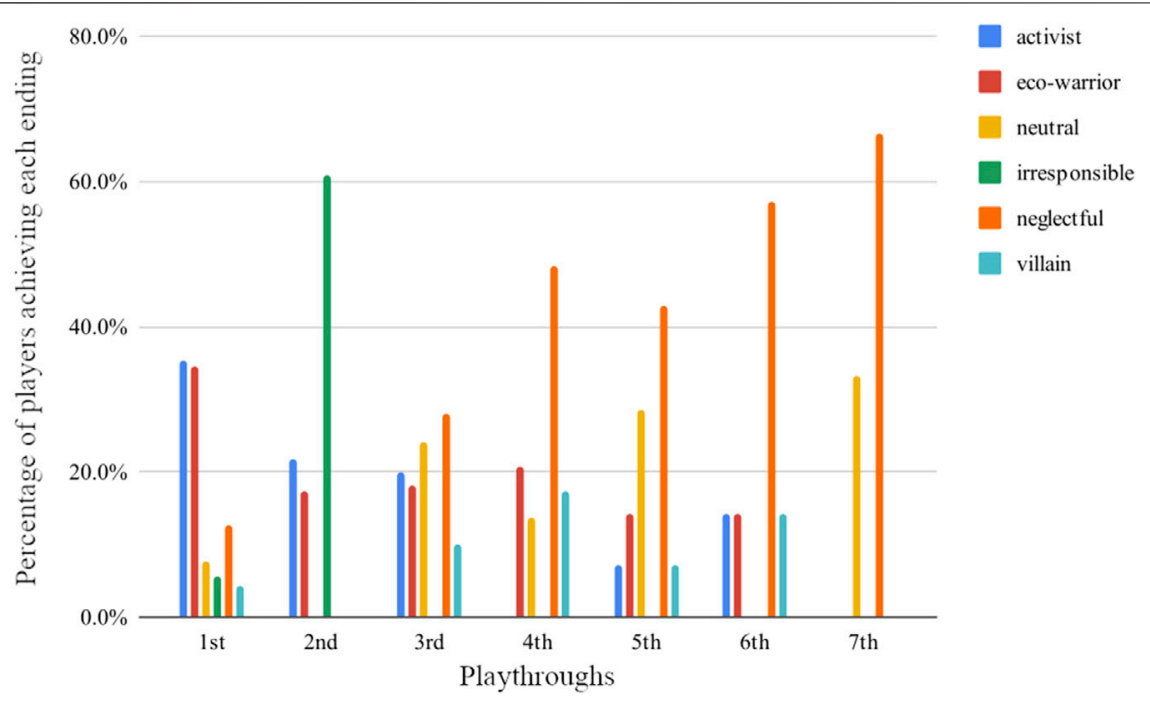

FIGURE 1 | Endings per playthrough. 


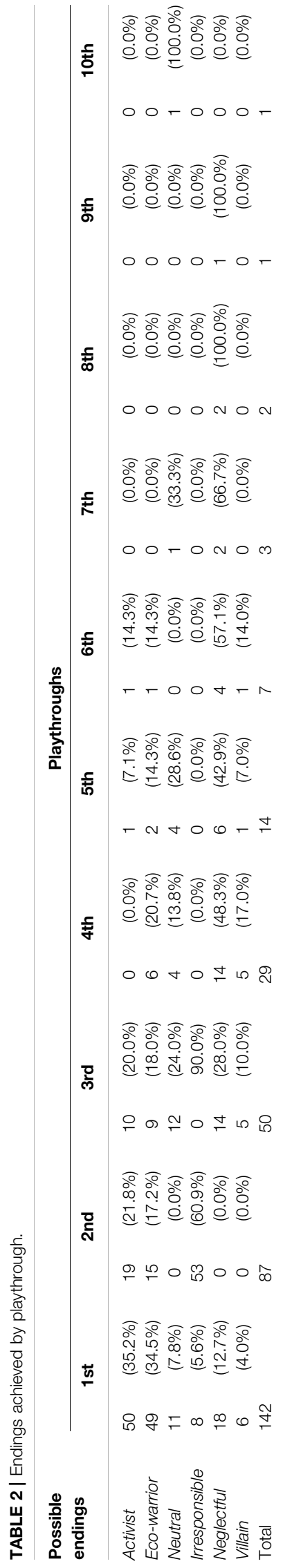

Reader/players had five options for the protests cycling link (see Table 6): in the first playthrough, they were evenly split between choosing the most activist option (brainstorming how to save resources) and the most passive option (doing nothing but watching everyone else) at 29.0 and $28.1 \%$, respectively. As replays progressed, reader/players trended more towards the passive option and the aggressive option (joining in with angry shouting).

The pop-up links produced binary data: they were either clicked/tapped or not. Each shows a high click rate in the initial playthrough $(62.0,61.3$, and $68.3 \%$; see Table 7), decreasing with each replay. While "Gens" seems to have a higher click rate on first playthrough than the previous two pop-ups, this difference is not significant.

\section{DISCUSSION}

It is important not to over-interpret this data. While much of the data demonstrate trends of some sort, some of these can be ascribed to the structure and environment of the workshops. With this caveat in mind, however, and accounting for these potential confounds, there are some interesting aspects of the playthrough data worth discussing, both with regard to participant attitudes towards climate change and to their engagement in the IDN.

It is encouraging that so many participants replayed NW4T so many times: more than one in five reader/players conducted four or more playthroughs. Not all replays were entirely voluntary; one of Workshop 2's instructions is for the students to find as many endings as they can, and they are given a worksheet to record the endings they encounter. Nonetheless, variation in the options they chose, including varying cycling links, shows that they were not simply clicking through the story; they were actively engaged in it, seeking out new options and pathways to explore with each playthrough. Timestamps on the replays also show that some reader/players accessed the work on different days, indicating they may have continued interacting with the IDN even outside of Workshop 2. While not entirely conclusive, this indicates that the IDN does connect to the target audience, at least enough for the students to actively engage with it in their classroom setting. They do not simply make the motions to click through in order to "look busy"; they are reading the story and making choices to affect its outcomes. Though collecting physiological data such as galvanic skin responses or eye-tracking were not within the scope of the study, and the large numbers of students prevented direct ethnographic observation to any significant extent, we can estimate that NW4T is achieving its goal of engaging the students on a personal level of entertainment, at least to some degree.

The data regarding the endings reader/players reach is similarly dampened by the instruction to find as many endings as possible; we cannot say for certain that the reader/ players are entirely voluntary in their engagement with the story themes and choices because of this instruction (Though it's important to note that classroom dynamics play a role here regarding whether or not students are inclined to follow 
TABLE 3 | Transport choices by playthrough.

\begin{tabular}{|c|c|c|c|c|c|c|c|c|c|c|c|c|c|c|c|c|c|c|c|c|}
\hline \multirow{2}{*}{$\begin{array}{l}\text { Transport } \\
\text { options }\end{array}$} & \multicolumn{20}{|c|}{ Playthroughs } \\
\hline & & 1st & & 2nd & & 3rd & & 4th & & 5th & & 6th & & 7th & & 8th & & 9th & & 10th \\
\hline Walk & 76 & (53.5\%) & 41 & (47.1\%) & 24 & (48.0\%) & 7 & (24.1\%) & 9 & (64.3\%) & 1 & (14.3\%) & 2 & (66.7\%) & 1 & (50.0\%) & 0 & $(0.0 \%)$ & 0 & (0.0\%) \\
\hline Monorail & 41 & (28.9\%) & 26 & (29.9\%) & 15 & (30.0\%) & 9 & (31.0\%) & 2 & (14.3\%) & 2 & (28.6\%) & 1 & (33.3\%) & 0 & $(0.0 \%)$ & 1 & $(100.0 \%)$ & 1 & (100.0\%) \\
\hline Solo-port & 25 & (17.6\%) & 20 & (23.0\%) & 11 & (22.0\%) & 13 & (44.8\%) & 3 & (21.4\%) & 4 & (57.1\%) & 0 & (0.0\%) & 1 & (50.0\%) & 0 & $(0.0 \%)$ & 0 & $(0.0 \%)$ \\
\hline Total & 142 & & 87 & & 50 & & 29 & & 14 & & 7 & & 3 & & 2 & & 1 & & 1 & \\
\hline
\end{tabular}

TABLE 4 | Lunch choices by playthrough.

\begin{tabular}{|c|c|c|c|c|c|c|c|c|c|c|c|c|c|c|c|c|c|c|c|c|}
\hline \multirow{2}{*}{$\begin{array}{l}\text { Lunch } \\
\text { options }\end{array}$} & \multicolumn{20}{|c|}{ Playthrough } \\
\hline & & 1st & & 2nd & & 3rd & & 4th & & 5th & & 6th & & 7th & & 8th & & 9th & & 10th \\
\hline Salad & 47 & (33.1\%) & 20 & (23.0\%) & 8 & (16.0\%) & 3 & (10.3\%) & 3 & (21.4\%) & 0 & (0.0\%) & 0 & (0.0\%) & 1 & (50.0\%) & 0 & $(0.0 \%)$ & 0 & (0.0\%) \\
\hline $\begin{array}{l}\text { Veggie } \\
\text { burger }\end{array}$ & 26 & (18.3\%) & 10 & (11.5\%) & 6 & (12.0\%) & 4 & (13.8\%) & 1 & $(7.1 \%)$ & 1 & (14.3\%) & 0 & (0.0\%) & 0 & $(0.0 \%)$ & 0 & $(0.0 \%)$ & 0 & (0.0\%) \\
\hline $\begin{array}{l}\text { Beef } \\
\text { burger }\end{array}$ & 40 & $(28.2 \%)$ & 7 & $(8.0 \%)$ & 4 & (8.0\%) & 4 & (13.8\%) & 1 & (7.1\%) & 2 & (28.6\%) & 0 & $(0.0 \%)$ & 0 & (0.0\%) & 0 & $(0.0 \%)$ & 0 & (0.0\%) \\
\hline Egg & 12 & (8.5\%) & 40 & (46.0\%) & 20 & (40.0\%) & 11 & (37.9\%) & 8 & (57.1\%) & 3 & (42.9\%) & 3 & (100.0\%) & 1 & (50.0\%) & 0 & $(0.0 \%)$ & 0 & (0.0\%) \\
\hline Protein & 17 & (12.0\%) & 10 & (11.5\%) & 12 & (24.0\%) & 7 & (24.1\%) & 1 & $(7.1 \%)$ & 1 & (14.3\%) & 0 & $(0.0 \%)$ & 0 & $(0.0 \%)$ & 1 & (100.0\%) & 1 & (100.0\%) \\
\hline Total & 142 & & 87 & & 50 & & 29 & & 14 & & 7 & & 3 & & 2 & & 1 & & 1 & \\
\hline
\end{tabular}

TABLE 5 | Activity choices by playthrough.

\begin{tabular}{|c|c|c|c|c|c|c|c|c|c|c|c|c|c|c|c|c|c|c|c|c|}
\hline \multirow{2}{*}{$\begin{array}{l}\text { Activity } \\
\text { options }\end{array}$} & \multicolumn{20}{|c|}{ Playthrough } \\
\hline & & 1st & & 2nd & & 3 rd & & 4th & & 5th & & 6th & & 7th & & 8th & & 9th & & 10th \\
\hline chool & 45 & $(31.7 \%)$ & 39 & (44.8\%) & 20 & $(40.0 \%)$ & 15 & (51.7\%) & 6 & (42.9\%) & 3 & (42.9\%) & 0 & $(0.0 \%)$ & 1 & (50.0\%) & 1 & (100.0\%) & 0 & $(0.0 \%)$ \\
\hline Skive off & 61 & $(43.0 \%)$ & 25 & (28.7\%) & 16 & $(32.0 \%)$ & 6 & (20.7\%) & 5 & (35.7\%) & 3 & (42.9\%) & 1 & (33.3\%) & 0 & $(0.0 \%)$ & 0 & $(0.0 \%)$ & 0 & $(0.0 \%)$ \\
\hline Total & 142 & & 87 & & 50 & & 29 & & 14 & & 7 & & 3 & & 2 & & 1 & & 1 & \\
\hline
\end{tabular}

TABLE 6 | Protest choices by playthrough.

\begin{tabular}{|c|c|c|c|c|c|c|c|c|c|c|c|c|c|c|c|c|c|c|c|c|}
\hline \multirow{2}{*}{$\begin{array}{l}\text { Protest } \\
\text { options }\end{array}$} & \multicolumn{20}{|c|}{ Playthrough } \\
\hline & & 1st & & 2nd & & 3rd & & 4th & & 5 th & & 6th & & 7th & & 8th & & 9th & & 10th \\
\hline $\begin{array}{l}\text { Save } \\
\text { food/fuel }\end{array}$ & 44 & (31.0\%) & 24 & $(27.6 \%)$ & 15 & (30.0\%) & 6 & $(20.7 \%)$ & 3 & $(21.4 \%)$ & 2 & $(28.6 \%)$ & 1 & (33.3\%) & 0 & $(0.0 \%)$ & 0 & $(0.0 \%)$ & 1 & $(100.0 \%)$ \\
\hline $\begin{array}{l}\text { Just } \\
\text { watch }\end{array}$ & 34 & (23.9\%) & 30 & $(34.5 \%)$ & 12 & $(24.0 \%)$ & 11 & $(37.9 \%)$ & 5 & (35.7\%) & 2 & $(28.6 \%)$ & 1 & (33.3\%) & 2 & $(100.0 \%)$ & 0 & $(0.0 \%)$ & 0 & $(0.0 \%)$ \\
\hline $\begin{array}{l}\text { Angry } \\
\text { shouting }\end{array}$ & 24 & (16.9\%) & 14 & (16.1\%) & 12 & (24.0\%) & 7 & (24.1\%) & 2 & (14.3\%) & 1 & (14.3\%) & 1 & (33.3\%) & 0 & (0.0\%) & 1 & (100.0\%) & 0 & (0.0\%) \\
\hline $\begin{array}{l}\text { Message } \\
\text { friends }\end{array}$ & 28 & $(19.7 \%)$ & 6 & $(6.9 \%)$ & 5 & (10.0\%) & 3 & $(10.3 \%)$ & 3 & $(21.4 \%)$ & 1 & $(14.3 \%)$ & 0 & $(0.0 \%)$ & 0 & $(0.0 \%)$ & 0 & $(0.0 \%)$ & 0 & $(0.0 \%)$ \\
\hline $\begin{array}{l}\text { Calm } \\
\text { people } \\
\text { down }\end{array}$ & 12 & (8.5\%) & 13 & (14.9\%) & 6 & (12.0\%) & 2 & (6.9\%) & 1 & $(7.1 \%)$ & 1 & (14.3\%) & 0 & $(0.0 \%)$ & 0 & $(0.0 \%)$ & 0 & (0.0\%) & 0 & $(0.0 \%)$ \\
\hline Total & 142 & & 87 & & 50 & & 29 & & 14 & & 7 & & 3 & & 2 & & 1 & & 1 & \\
\hline
\end{tabular}

instructions). Nonetheless, the trends in the narrative pathways they chose does show us something of their attitudes towards the topic. More than two-thirds (69.7\%) made choices in their first playthrough that led to active and climate-positive endings; if the neutral ending is included, that proportion is $77.5 \%$. In the second playthrough, this combined proportion drops to $39.1 \%$, while the climate-damaging endings are the larger proportion. This indicates that the students deliberately chose options in their second playthrough that were the opposite of their first choices, resulting in a very different ending; $47.1 \%$ of reader/players who replayed the IDN at least once showed this positive-negative pattern. Notably, $28.2 \%$ of students got a positive ending in both 
TABLE 7 | Pop-up links clicked by playthrough.

\begin{tabular}{|c|c|c|c|c|c|c|c|c|c|c|c|c|c|c|c|c|}
\hline \multirow{3}{*}{$\begin{array}{l}\text { Pop-up links } \\
\text { Earth } 2.0\end{array}$} & \multicolumn{16}{|c|}{ Proportion of each pop-up link clicked by playthrough } \\
\hline & \multicolumn{2}{|c|}{ 1st } & \multicolumn{2}{|r|}{ 2nd } & \multicolumn{2}{|r|}{ 3rd } & \multicolumn{2}{|r|}{ 4th } & \multicolumn{2}{|r|}{ 5th } & \multicolumn{2}{|r|}{ 6th } & \multicolumn{2}{|r|}{ 7th } & \multicolumn{2}{|r|}{8 th $^{a}$} \\
\hline & 88 & $(62.0 \%)$ & 25 & $(28.7 \%)$ & 11 & $(22.0 \%)$ & 2 & $(6.9 \%)$ & 2 & $(14.3 \%)$ & 0 & $(0.0 \%)$ & 0 & $(0.0 \%)$ & 0 & $(0.0 \%)$ \\
\hline The deeps & 87 & $(61.3 \%)$ & 28 & $(32.2 \%)$ & 16 & (32.0\%) & 9 & (31.0\%) & 3 & $(21.4 \%)$ & 2 & $(28.6 \%)$ & 1 & $(100.0 \%)$ & 1 & $(100.0 \%)$ \\
\hline Gens & 97 & (68.3\%) & 33 & (37.9\%) & 10 & (20.0\%) & 8 & $(27.6 \%)$ & 2 & $(14.3 \%)$ & 0 & $(0.0 \%)$ & 0 & $(0.0 \%)$ & 0 & $(0.0 \%)$ \\
\hline Total potential clicks & 142 & & 87 & & 50 & & 29 & & 14 & & 7 & & 1 & & 1 & \\
\hline
\end{tabular}

${ }^{a}$ No pop-up links were clicked on the 9th and 10th playthroughs.

of their first two playthroughs, and after the second playthrough the positive endings return as the majority proportion. This indicates that, while the students were following the instructions to find all the endings, their initial and enduring tendencies were to make positive choices regarding climate change action. Given the collected data, it is impossible to determine the students' internal motivations for these positive choices, whether from genuine desire to "do good", knowledge and understanding of climate change, or awareness of what the "expected" choices might be. Future study is needed to reveal more individualistic and psychological motivations; our forthcoming paper (Horry et al. in review) is a step in this direction.

The cycling link is a unique function of these sorts of IDNs (especially in Twine), and thus less familiar to Internet users than standard transitional hyperlinks. That the transport link, the first of these in NW4T, remains at "walking" for most initial playthroughs shows that most reader/players simply didn't click that unfamiliar type of link, progressing to the next passage without changing the option. The plethora of links and options on the next passage, however, encourages them to begin playing in earnest: the lunch options vary more, though the default choice "salad" still comes out on top. By the time they reach the activity cycling link at the bottom of that same passage, they are actively cycling through the options to choose deliberately: $43.0 \%$ choose to "skive off" rather than stay with the default choice of going back to "school". These patterns indicate strong intuitive familiarity with new conventions related to the narrative form, quite early in the course of the IDN (by the sixth passage).

The protests cycling link reveals a small but important detail about the choices teens make with regard to climate action. This is the first significant choice in the IDN (on the tenth passage) that sets the reader/player down the pathway to a specific ending. As noted, most reader/players' early playthroughs result in positive endings, which is reflected in the $29.0 \%$ of them who choose the most activist option of the protests cycling link (brainstorming how to save resources). Yet approximately the same number of reader/players $(28.1 \%)$ choose the passive option (just waiting and watching). This is the default choice on this link, though we have established above that by this point, the reader/players are familiar with cycling links enough to change them from their default option. This option remained high in subsequent replays, even as the reader/players were opting for varying outcomes. While no definitive conclusions can be drawn from such a finite choice point, it nonetheless could be an indicator that either the reader/players feel they do not have sufficient control and self-efficacy to enact change, or they are uncertain as to what their actions should be. As with the trend for positive choices, this is an area that requires expanding in future studies.

Finally, the click rates on the pop-up links indicate excellent familiarity with the conventions of the IDN by the time these links appear (starting on the sixth passage). That they have high click rates that are sustained for each pop-up link also shows that the reader/players are strongly engaged in the narrative: more than $60 \%$ of them click to get more information about the narrative.

Overall, the playthrough data from students interacting with No World 4 Tomorrow tell us that the students are strongly engaging with the IDN, quickly becoming familiar with its unique narrative conventions. The choices they make indicate positive attitudes towards climate change action, in line with the initial survey data we have analysed (Rudd et al., 2019; Horry et al. in review). It is likely, however, that these young people struggle with the notion of taking action as individuals, particularly when it comes to encouraging both their peers and their elders to do so as well. We are currently expanding our research into more longitudinal studies to examine how well the lessons learned in the fictional context transfer to the complexities of real-world behaviours and actions. More work is needed to communicate and encourage appropriate action.

\section{DATA AVAILABILITY STATEMENT}

The raw data supporting the conclusion of this article will be made available by the authors, without undue reservation.

\section{ETHICS STATEMENT}

The studies involving human participants were reviewed and approved by the Swansea University. Written informed consent to participate in this study was provided by the participants' legal guardian/next of kin.

\section{AUTHOR CONTRIBUTIONS}

Conceptualisation, RLS, JAR, RH, and HR, and methodology, RLS; formal analysis, RLS; investigation, JAR, RLS, and RH; 
writing-original draft preparation, RLS; writing-review and editing, JAR, RH, and HR; project administration, JAR; funding acquisition, JAR, RLS, and RH. All authors have read and agreed to the published version of the article.

\section{FUNDING}

This research was funded by United Kingdom EPSRC, through the Impact Acceleration Account grant EP/R511614/1

\section{REFERENCES}

A Singhal, MJ. Cody, EM. Rogers, and M Sabido (Editors) (2003). EntertainmentEducation and Social Change: History, Research, and Practice (Oxfordshire UK: Routledge).

Albertalli, B. (2015). Simon vs. The Homo Sapiens Agenda. London, UK: Penguin.

Anderson, C. (2006). The Long Tail: Why the Future of Business Is Selling Less of More. Paris: Hachette.

Bacigalupi, P. (2010). Ship Breaker. Paris: Hachette.

Bostrom, A., Hayes, A. L., and Crosman, K. M. (2019). Efficacy, Action, and Support for Reducing Climate Change Risks. Risk Anal. 39 (4), 805-828. doi:10.1111/risa.13210

Brown, J. S., and Adler, R. P. (2008). Minds on Fire: Open Education, the Long Tail, and Learning 2.0. Educ. Rev. 43 (1), 16-32. Available at https://er. educause.edu/articles/2008/1/minds-on-fire-open-education-the-long-tailand-learning-20

Cheng, M.-T., Chen, J.-H., Chu, S.-J., and Chen, S.-Y. (2015). The Use of Serious Games in Science Education: A Review of Selected Empirical Research from 2002 to 2013. J. Comput. Educ. 2 (3), 353-375. doi:10.1007/s40692-015-0039-9

Cope, B., and Kalantzis, M. (2009). "Multiliteracies": New Literacies, New Learning. Pedagogies: Int. J. 4 (3), 164-195. doi:10.1080/15544800903076044

Cornelius, M., Armel, K. C., Hoffman, K., Allen, L., Bryson, S. W., Desai, M., et al. (2014). Increasing Energy- and Greenhouse Gas-Saving Behaviors Among Adolescents: A School-Based Cluster-Randomized Controlled Trial. Energy Efficiency 7 (2), 217-242. doi:10.1007/s12053-013-9219-5

Dahlstrom, M. F. (2014). Using Narratives and Storytelling to Communicate Science with Nonexpert Audiences. Proc. Natl. Acad. Sci. 111 (Suppl. ment_4), 13614-13620. doi:10.1073/pnas.1320645111

Dashner, J. (2013). The Maze Runner. Frome: Chicken House.

Ensslin, A., Skains, L., Riley, S., Haran, J., Mackiewicz, A., and Halliwell, E. (2016). Exploring Digital Fiction as a Tool for Teenage Body Image Bibliotherapy. Digital Creativity 27 (3), 177-195. doi:10.1080/14626268.2016.1210646

Estyn (2018). The Annual Report of Her Majesty's Chief Inspector of Education and Training in Wales 2017-2018. Available at: https://www. estyn.gov.wales/document/annual-report-2017-2018.

Ferrara, J. (2013). Games for Persuasion: Argumentation, Procedurality, and the Lie of Gamification. Games Cult. 8 (4), 289-304. doi:10.1177/ 1555412013496891

Gifford, R. (2011). The Dragons of Inaction: Psychological Barriers that Limit Climate Change Mitigation and Adaptation. Am. Psychol. 66 (4), 290-302. doi: $10.1037 / \mathrm{a} 0023566$

Griffin, P. (2017). CDP Carbon Majors Report 2017. CDP Report 2017.

Harker-Schuch, I. E., Mills, F. P., Lade, S. J., Colvin, R. M., and Colvin, R. M. (2020). CO2peration - Structuring a 3D Interactive Digital Game to Improve Climate Literacy in the 12-13-Year-Old Age Group. Comput. Edu. 144 (January), 103705-103716. doi:10.1016/j.compedu.2019.103705

Höppner, C., and Whitmarsh, L. (2011). "Public Engagement in Climate Action: Policy and Public Expectations," in Engag. Public Clim. Change Behav. Change Commun. Editors I. Lorenzoni, L. Whitmarsh, and S. O'Neill (Oxfordshire UK: Routledge), 47-65.

Horry, R., Rudd, J. A., Skains, R. L., and Ross, H. (in review). Development and Validation of the Climate Capability Scale. J. Environ. Psychol. administered by Swansea University. Swansea University Research Grant Enabler Funding supported the expansion of the project to a second school. We also thank the Welsh Crucible for financial support.

\section{ACKNOWLEDGMENTS}

The authors would like to thank the participating schools, teachers, students, and parents.

Huffaker, D. A., and Calvert, S. L. (2003). The New Science of Learning: Active Learning, Metacognition, and Transfer of Knowledge in E-Learning Applications. J. Educ. Comput. Res. 29 (3), 325-334. doi:10.2190/4T8930W2-DHTM-RTQ2

Klimas, C. (2009). Twine. Available at: http://twinery.org.

Lester, J. C., Spires, H. A., Nietfeld, J. L., Minogue, J., Mott, B. W., and Lobene, E. V. (2014). Designing Game-Based Learning Environments for Elementary Science Education: A Narrative-Centered Learning Perspective. Inf. Sci. 264 (April), 4-18. doi:10.1016/j.ins.2013.09.005

Lutz, J. (2001). Riding the Horseless Carriage to the Computer Revolution: Teaching History in the Twenty-First century. Hist. Soc. Soc. Hist. 34 (68), 427-435. doi:10.1109/mc.2001.920609

Mayer, R. E. (2014). Computer Games for Learning: An Evidence-Based Approach. Cambridge, MA: The MIT Press.

Moezzi, M., Janda, K. B., and Rotmann, S. (2017). Using Stories, Narratives, and Storytelling in Energy and Climate Change Research. Energ. Res. Soc. Sci. 31 (September), 1-10. doi:10.1016/j.erss.2017.06.034

Nicieza, F., and Liefeld, R. (1991). Deadpool. New York: Marvel Comics.

Pardeck, J. T. (2014). Using Books in Clinical Social Work Practice: A Guide to Bibliotherapy. New York: Routledge.

Pruneau, D., Liboiron, L., Vrain, E., Gravel, H., Bourque, W., and Langis, J. (2001). People's Ideas about Climate Change: A Source of Inspiration for the Creation of Educational Programs. Can. J. Environ. Educ. 6, 121-138.

Rabinovich, A., Morton, T. A., and Duke, C. C. (2011). "Collective Self and Individual Choice: The Role of Social Comparisons in Promoting Public Engagement with Climate Change," in Engag. Public Clim. Change Behav. Change Commun. Editors I. Lorenzoni, L. Whitmarsh, and S. O'Neill (Oxfordshire UK: Routledge), 47-65.

Rapeepisarn, K., Wong, K. W., Fung, C. C., and Arnold, D. (2006). "Similarities and Differences between 'Learn through Play' and 'Edutainment," in Proceedings of the 3rd Australasian conference on Interactive entertainment, Perth, Australia, December 4-6, 2006.

Resnick, M. (2004). Edutainment? No Thanks. I Prefer Playful Learning. Assoc. Civita Rep. Edutainment. Available at: https://lk.media.mit.edu/papers/edutainment.pdf.

Ross, H., Rudd, J. A., Skains, R. L., and Horry, R. (20211961). How Big Is My Carbon Footprint? Understanding Young People's Engagement with Climate Change Education. Sustainability 13, 1961. doi:10.3390/su13041961

Rudd, J. A., Horry, R., and Skains, R. L. (2019). You and CO2: A Public Engagement Study to Engage Secondary School Students with the Issue of Climate Change. J. Sci. Educ. Technol. 29, 230-241. doi:10.1007/s10956-019-09808-5

Skains, L. (2019a). "No World 4 Tomorrow." Hyperfiction. You and CO2. 2019. Available at: http://youandco2.org/NW4T/.

Skains, R. L., Rudd, J. A., Casaliggi, C., Hayhurst, E., Ruth, H., Ross, H., et al. (2019). "Entertaining to Educate: Creative and Pedagogical Insights," in Using Interact. Digit. Narrat. Sci. Health Educ. (Bingley, UK: Emerald Publishing), 55-72.

Skains, R. L. (2019b). Teaching Digital Fiction: Integrating Experimental Writing and Current Technologies." Palgrave Commun. Available at: https://www. nature.com/articles/s41599-019-0223-z.

Sood, S., Menard, T., and Kim, W. (2003). "The Theory behind EntertainmentEducation," in Entertain.-Educ. Soc. Change Hist. Res. Pract. Editors A. Singhal, M. J. Cody, E. M. Rogers, and M. Sabido (Oxfordshire UK: Routledge), 117-149.

UK Government (2019). School Performance: Ofsted Ratings. Available at: https://www.compare-school-performance.service.gov.uk/schools-by-type? step $=$ default\&table $=$ schools\&region $=$ all-england $\&$ for $=$ ofsted . 
United Nations (2016). “Climate Change.” United Nations. Available at: https:// www.un.org/en/sections/issues-depth/climate-change/index.html.

von Borries, R., Guinto, R., Thomson, D. J., Abia, W. A., and Lowe, R. (2020). Planting Sustainable Seeds in Young Minds: The Need to Teach Planetary Health to Children. Lancet Planet. Health 4 (11), e501-e502. doi:10.1016/ S2542-5196(20)30241-2

Wegner, D. M., and Schaefer., D. (1978). The Concentration of Responsibility: An Objective Self-Awareness Analysis of Group Size Effects in Helping Situations. J. Personal. Soc. Psychol. 36 (2), 147-155. doi:10.1037/0022-3514.36.2.147

Conflict of Interest: The authors declare that the research was conducted in the absence of any commercial or financial relationships that could be construed as a potential conflict of interest.
Publisher's Note: All claims expressed in this article are solely those of the authors and do not necessarily represent those of their affiliated organizations, or those of the publisher, the editors and the reviewers. Any product that may be evaluated in this article, or claim that may be made by its manufacturer, is not guaranteed or endorsed by the publisher.

Copyright (๑) 2022 Skains, Rudd, Horry and Ross. This is an open-access article distributed under the terms of the Creative Commons Attribution License (CC BY).

The use, distribution or reproduction in other forums is permitted, provided the original author(s) and the copyright owner(s) are credited and that the original publication in this journal is cited, in accordance with accepted academic practice. No use, distribution or reproduction is permitted which does not comply with these terms. 